\title{
A Rapid Review of COVID-19 Vaccine Prioritization in the U.S.: Alignment between Federal Guidance and State Practice
}

\author{
Vageesh Jain $^{1, *}$, Lara Schwarz ${ }^{2}$ and Paula Lorgelly ${ }^{3}$ (D) \\ 1 Institute for Global Health, University College London, London WC1N 1EH, UK \\ 2 Herbert Wertheim School of Public Health and Human Longevity Science, University of California San Diego, \\ La Jolla, CA 92093, USA; Inschwar@health.ucsd.edu \\ 3 Institute of Epidemiology and Health Care, University College London, London WC1E 7HB, UK; \\ p.lorgelly@ucl.ac.uk \\ * Correspondence: vageesh.jain@ucl.ac.uk
}

Citation: Jain, V.; Schwarz, L.; Lorgelly, P. A Rapid Review of COVID-19 Vaccine Prioritization in the U.S.: Alignment between Federal Guidance and State Practice. Int. J. Environ. Res. Public Health 2021, 18, 3483. https://doi.org/10.3390/ ijerph18073483

Academic Editor: Paul B. Tchounwou

Received: 12 March 2021

Accepted: 25 March 2021

Published: 27 March 2021

Publisher's Note: MDPI stays neutral with regard to jurisdictional claims in published maps and institutional affiliations.

Copyright: (c) 2021 by the authors. Licensee MDPI, Basel, Switzerland. This article is an open access article distributed under the terms and conditions of the Creative Commons Attribution (CC BY) license (https:// creativecommons.org/licenses/by/ $4.0 /)$.

\begin{abstract}
Background: Population groups to be prioritized for COVID-19 vaccinations in the U.S. have been determined at the Federal level, but there is variation in how States have implemented guidance. This review examines how the position of population groups in vaccine priority lists varies between Federal guidance and State practice. Methods: An online search of State vaccination prioritization plans was conducted. Data were extracted on each population group included and their relative position. A standardized ranking method was applied to provide a directional measure of variability in prioritization between State and Federal guidance, for each population group. Results: Healthcare workers and those in long-term care facilities were largely prioritized in line with Federal guidance. Aside from early education staff, essential workers were often excluded at State level. Almost all States included the 65-74 year age group and most assigned them to a higher position than recommended in Federal guidance. Those with underlying medical conditions were similarly highly prioritized, although there was more variability across States. Some socially vulnerable groups (not included in Federal guidance) were highly prioritized by many States. Conclusions: The prioritization of groups for COVID-19 vaccination has been highly variable despite clear Federal guidance. Future guidance must be relevant to local needs, values, and constraints, to minimize any unwarranted heterogeneity in vaccine access across populations.
\end{abstract}

Keywords: public health; health policy; health economics

\section{Introduction}

Health inequities are differences in health that are unnecessary, avoidable, unfair and unjust [1]. Vertical equity refers to the preferential allocation of resources to those most in need. Although it is expected that all of the United States (U.S.) population will be offered a COVID-19 vaccine eventually, with limited initial supplies, an equitable allocation would involve prioritizing those who are most at need. Having a robust, scientific and nationally standardized process is essential, as the health and socioeconomic impacts of the pandemic vary greatly across population groups.

Federalism, or the division of power between a national government and States, is a fundamental feature of U.S. public health governance. The Centers for Disease Control and Prevention (CDC) - the leading Federal public health agency in the U.S.- - has limited authority to direct local officials to take united action [2]. For example, the power to quarantine individuals rests primarily with State and local authorities, and there is substantial variation between jurisdictions [3]. Despite clear CDC guidance [4], 13 States still have no mandatory public facemask policy as of March 2021. Arguably, it is possible for a Federalist public health system to respond equitably to a pandemic, but this would require robust Federal guidelines that reflect local needs and values, and their effective implementation. 
The population groups to be prioritized for COVID-19 vaccination in the U.S. were determined by the Advisory Committee on Immunization Practices (ACIP), in the CDC. The foremost groups recommended for vaccination ahead of others include healthcare workers and those in long-term care facilities (Table 1). The guidance does not explicitly account for social vulnerability (a risk factor for disease acquisition and severity [5]), instead advising States to consider this at all stages of prioritization. Despite clear Federal guidance, current evidence suggests there is significant variation in the way States are choosing to prioritize population groups for vaccination [6-8]. To some extent this may be warranted given the responsibility of States to tailor central guidance to the needs of their local population. However, where there is systematic variability in the position of some population groups, this indicates that Federal guidance is limited in scope and relevance.

Table 1. Centers for Disease Control and Prevention (CDC) guidance summary and definitions.

\begin{tabular}{|c|c|c|}
\hline Phase & Population Group & Definitions \\
\hline \multirow{2}{*}{$1 \mathrm{~A}$} & Healthcare personnel & $\begin{array}{l}\text { Paid and unpaid persons serving in healthcare settings } \\
\text { who have the potential for direct or indirect exposure to } \\
\text { patients or infectious materials }\end{array}$ \\
\hline & $\begin{array}{l}\text { Long-term care } \\
\text { facility residents }\end{array}$ & $\begin{array}{l}\text { Adults who reside in facilities that provide a range of } \\
\text { services, including medical and personal care, to } \\
\text { persons who are unable to live independently }\end{array}$ \\
\hline \multirow[t]{2}{*}{$1 \mathrm{~B}$} & Frontline essential workers & $\begin{array}{l}\text { First responders (e.g., firefighters and police officers), } \\
\text { corrections officers, food and agricultural workers, U.S. } \\
\text { Postal Service workers, manufacturing workers, grocery } \\
\text { store workers, public transit workers, and those who } \\
\text { work in the education sector (teachers and support staff } \\
\text { members) as well as child care workers }\end{array}$ \\
\hline & People aged 75 and older & People aged 75 and older \\
\hline \multirow{3}{*}{$1 \mathrm{~B}$} & People aged $65-74$ years & People aged $65-74$ years \\
\hline & $\begin{array}{l}\text { People aged } 16-64 \text { years } \\
\text { with underlying medical } \\
\text { conditions }\end{array}$ & $\begin{array}{l}\text { Conditions include cancer; chronic kidney disease; } \\
\text { chronic obstructive pulmonary disease (COPD); heart } \\
\text { conditions, such as heart failure, coronary artery disease, } \\
\text { or cardiomyopathies; immunocompromised state } \\
\text { (weakened immune system) from solid organ transplant; } \\
\text { obesity (body mass index [BMI] } \geq 30 \mathrm{~kg} / \mathrm{m}^{2} \text { but } \\
<40 \mathrm{~kg} / \mathrm{m}^{2} \text { ); severe obesity (BMI } \geq 40 \mathrm{~kg} / \mathrm{m}^{2} \text { ); sickle } \\
\text { cell disease; smoking; type } 2 \text { diabetes mellitus; } \\
\text { and pregnancy }\end{array}$ \\
\hline & Other essential workers & $\begin{array}{l}\text { Those working in transportation and logistics, water } \\
\text { and wastewater, food service, shelter and housing (e.g., } \\
\text { construction), finance (e.g., bank tellers), information } \\
\text { technology and communications, energy, legal, media, } \\
\text { public safety (e.g., engineers), and public health workers }\end{array}$ \\
\hline
\end{tabular}

This paper examines how the position of different population groups in vaccine priority lists varies between Federal guidance and State practice, and which population groups (included in State priority lists) were not included in Federal guidance. This will further our understanding of how Federal guidance on priority groups can be improved, in order to facilitate a more equitable national allocation of vaccines. Given manufacturing and storage limitations, the possibility of novel variants and waning immunity, this study may also inform the rollout of future COVID-19 vaccination programs, as well as future infectious disease vaccination responses. 


\section{Methods}

\subsection{Definitions and Sources}

Recommendations on COVID-19 vaccine priority groups and their definitions, issued at the Federal level by the CDC, were accessed online [9-11] (Table 1). Currently, this guidance proposes prioritizing seven high-risk population groups in the first phase of vaccination. This phase can be split further into three levels of priority $(1 \mathrm{~A}-1 \mathrm{C})$, with those in $1 \mathrm{~A}$ receiving vaccines before $1 \mathrm{~B}$, and those in $1 \mathrm{~B}$ receiving vaccines before $1 \mathrm{C}$, although some overlap is expected given variations in populations, group definitions and vaccine supplies. Multiple groups are included within each phase, for instance with both health workers and those in long-term care facilities to be vaccinated in parallel during phase $1 \mathrm{~A}$, as the top priority groups. Following the first phase, the remainder of the general population (aged 16+) is to be vaccinated in phase two. No further prioritization within the general population has been so far recommended by the CDC [11]. Definitions of population groups and the phase in which individual States, plus Washington D.C., prioritized them were obtained from publicly available documents, published on official State Department of Health websites.

\subsection{Data Extraction}

The online search of State guidance was conducted by one reviewer (VJ) from 14 to 18 February 2021 and repeated by a second reviewer (LS) from 26 February to 2 March. The second reviewer was blinded to any previous results, but was provided with the same data extraction framework used by the first reviewer, to ensure comparability of findings. Where both reviewers recorded the inclusion or position of groups differently, those particular State priority lists were re-visited and it was determined whether guidance had changed between the two independent reviews, or there was a discrepancy in interpretation between reviewers. All such instances were discussed until agreement was reached on the appropriate inclusion or position of groups.

All data were extracted to Microsoft Excel, enabling a comparison of how population groups are prioritized by individual States. All groups specified by individual States were recorded as written in State guidance, including where there were minor differences in the definitions of groups. The position of a particular group in a State priority list was also extracted as written in official guidance, regardless of States numbering groups differently. The resulting database is available from the authors on request.

\subsection{Data Analysis}

Some groups were aggregated to improve comparability with Federal guidance. This included grouping various age bands (e.g., 65-70 years) into the relevant (75+ or 65-74) groups recommended by the CDC. Those with existing medical conditions (of any age and any number of conditions) were aggregated into one group for analysis due to the use of various age thresholds for those with conditions, across States. Some groups included in State priority lists were explicitly not aggregated for analysis, as considering them distinctly revealed important differences. This included healthcare workers: separated into inpatient and outpatient/community services as well as frontline essential workers, with first responders (in turn stratified into medical and non-medical) and early education staff analyzed separately. In all cases, individual groups were compared with the most relevant Federal guidance benchmark.

The phase in which different groups were positioned by States was converted into a standardized ranking, to negotiate differences in the way States labelled priority groups. For instance, some States referred to 'phase 2' as the second stage of the vaccine rollout (including the second-highest priority groups), but in others it was the fourth stage, following three distinct phases from $1 \mathrm{~A}$ to $1 \mathrm{C}$. For this reason, each population group was considered by whether they were in the first, second, third, fourth or later prioritized phases, for a particular State. This enabled comparison with the three ordered phases set out by Federal guidance (1A-C). Where States included subgroups within a phase (e.g., 1A.1, 1A.2, 1A.3) 
these were treated as part of the same single phase (1A). Both reviewers involved in data extraction aggregated the data for each population group in this way and discussed any disagreements until consensus was reached.

Overall alignment with Federal guidance was considered in two steps. First, the total number of States including a population group in their vaccination plan was aggregated. Then, using the standardized ranking method outlined above, the total number of States using the same phase as recommended by the $\mathrm{CDC}$, the total number positioning a group ahead of (higher-priority) and the total number positioning a group behind (lower-priority) Federal guidance, was calculated. This provided a directional measure of variability between State practice and Federal guidance, for each included population group.

Many States had explicitly included populations groups that were not covered in the Federal guidance. These groups, as well as the phase of vaccination prioritization plans in which they were included, were summarized separately in a descriptive table.

\section{Results}

Table 2 demonstrates that all U.S. States prioritized frontline healthcare workers and those in long-term care facilities for vaccination as per Federal guidance. Unlike other States, Rhode Island included long-term care settings within a wider group initially prioritized for vaccines: congregate settings. Although Federal guidance makes no distinction between healthcare workers based in hospitals or directly caring for COVID-19 patients and others (e.g., pharmacists, dentists), six States assigned a lower priority to those in the latter group. First responders were one single group in Federal guidance, including health (e.g., paramedic) and non-health (e.g., police/fire) workers. In State guidance, these groups were often prioritized differently. Medical first responders were prioritized ahead of the indicated position in Federal guidance, alongside other healthcare workers, in 32 States. Other first responders were more commonly prioritized in phase 1B as per Federal guidance, although still assigned a higher priority position in 14 States.

Essential workers were excluded from many State priority lists. Of the 37 States including frontline essential workers, 12 assigned them to a lower priority than recommended in Federal guidance. Most States included early education staff (including K-12 school and childcare workers) at the recommended position, albeit on their own in many cases, rather than as part of the wider essential workforce as recommended by the CDC. Other essential workers (placed in the third phase of Federal recommendations) were included on only 22 State priority lists, although at the recommended Federal position in the majority of cases where present.

Only 18 States included priority age groups of 70 or 75 years and over, with the majority using lower age thresholds. Although 47 States included 65-74 age groups, 36 assigned them to a higher priority than Federal guidance. Those with underlying medical conditions were also commonly included in State priority lists. For this group, there was more variability in how they were prioritized, with 20 out of 40 States assigning a higher priority and 6 assigning a lower priority, compared to Federal guidance.

Several other groups were prioritized by States, and not included in Federal guidance (Table 3). Those living or working in congregate settings were explicitly included in the priority lists of 28 States. In the majority of cases they were included in the very first or second phase of a State's vaccine rollout. Although this group would be expected to include both homeless and prison populations, these terms were explicitly described in only 20 and 9 State priority lists, respectively. Individuals living with mental, physical or developmental disabilities were also a commonly identified and highly prioritized group, in 10 States. Other socially vulnerable groups including indigenous or tribal populations, Medicaid beneficiaries, and low-income groups were included in very few State priority lists. 
Table 2. State alignment with CDC guidance on COVID-19 vaccine prioritization.

\begin{tabular}{|c|c|c|c|c|c|}
\hline Population Group & $\begin{array}{c}\text { CDC } \\
\text { Recommended } \\
\text { Priority Phase }\end{array}$ & $\begin{array}{l}\text { Number of States } \\
\text { Including in Plans } \\
\quad(\mathrm{n}=51)\end{array}$ & $\begin{array}{c}\text { Number of States } \\
\text { Aligned }\end{array}$ & $\begin{array}{c}\text { Number of States } \\
\text { Assigning } \\
\text { Higher-Priority }\end{array}$ & $\begin{array}{l}\text { Number of States } \\
\text { Assigning } \\
\text { Lower-Priority }\end{array}$ \\
\hline Frontline health workers & $1 \mathrm{~A}$ & 51 & 51 & 0 & 0 \\
\hline $\begin{array}{l}\text { Long-term care } \\
\text { staff/residents }\end{array}$ & $1 \mathrm{~A}$ & 50 & 50 & 0 & 0 \\
\hline Other health workers & $1 \mathrm{~A}$ & 47 & 41 & 0 & 6 \\
\hline First responders (EMS) & $1 B$ & 47 & 12 & 32 & 3 \\
\hline First responders (other) & $1 \mathrm{~B}$ & 45 & 25 & 16 & 4 \\
\hline Early education staff & $1 \mathrm{~B}$ & 47 & 38 & 4 & 5 \\
\hline $\begin{array}{l}\text { Frontline essential } \\
\text { workers }\end{array}$ & $1 \mathrm{~B}$ & 37 & 23 & 2 & 12 \\
\hline Age $75+{ }^{a}$ & $1 B$ & 18 & 15 & 2 & 1 \\
\hline Age $65-74^{\mathrm{b}}$ & $1 C$ & 47 & 11 & 36 & 0 \\
\hline $\begin{array}{l}\text { Age 16-64 with high-risk } \\
\text { medical condition }{ }^{c}\end{array}$ & $1 C$ & 40 & 14 & 20 & 6 \\
\hline Other essential workers & $1 \mathrm{C}$ & 22 & 15 & 2 & 5 \\
\hline
\end{tabular}

a includes States where the prioritized age-group was $70+{ }^{b}$ includes States where the prioritized age-group was $65+$ (i.e., no upper limit);

${ }^{\mathrm{c}}$ Includes States where high-risk medical conditions group had no age restriction.

Table 3. Other population groups prioritized by States.

\begin{tabular}{|c|c|c|c|c|c|}
\hline Population Group & $\begin{array}{l}\text { Number of States } \\
\text { Including in Plans }\end{array}$ & $\begin{array}{l}\text { Number of States } \\
\text { Prioritizing First }\end{array}$ & $\begin{array}{l}\text { Number of States } \\
\text { Prioritizing Second }\end{array}$ & $\begin{array}{l}\text { Number of States } \\
\text { Prioritizing Third }\end{array}$ & $\begin{array}{l}\text { Number of States } \\
\text { Prioritizing Fourth } \\
\text { or Below }\end{array}$ \\
\hline $\begin{array}{l}\text { Working/living in } \\
\text { congregate settings, e.g., } \\
\text { prisons, homeless } \\
\text { shelters, group homes, } \\
\text { emergency shelters, } \\
\text { adult/child protective } \\
\text { services }\end{array}$ & 28 & 6 & 13 & 9 & 0 \\
\hline $\begin{array}{l}\text { Individuals with } \\
\text { disabilities }\end{array}$ & 10 & 3 & 6 & 0 & 1 \\
\hline Age 50-64 & 7 & 1 & 3 & 1 & 2 \\
\hline Age 60 and over & 5 & 0 & 2 & 3 & 0 \\
\hline $\begin{array}{l}\text { Those with moderate-risk } \\
\text { conditions }\end{array}$ & 4 & 0 & 1 & 1 & 2 \\
\hline $\begin{array}{l}\text { Indigenous or Tribal } \\
\text { populations }\end{array}$ & 4 & 1 & 1 & 1 & 1 \\
\hline Age 55-64 & 2 & 0 & 0 & 2 & 0 \\
\hline Medicaid beneficiaries & 2 & 0 & 1 & 1 & 0 \\
\hline $\begin{array}{l}\text { Low-income/living in } \\
\text { affordable housing }\end{array}$ & 2 & 0 & 2 & 0 & 0 \\
\hline Age 40 and over & 1 & 0 & 1 & 0 & 0 \\
\hline
\end{tabular}

\section{Discussion}

\subsection{Key Findings}

For healthcare workers and those in long-term care facilities, there was almost complete concordance between individual State vaccine priority lists and Federal recommendations. Notably first responders were not prioritized in the same way as advised by Federal guidance with medical first responders more often placed ahead of the recommended Federal position and in front of other (non-health) first responders. Many States excluded essential workers from priority lists, and where included they were often assigned a lower 
priority position compared to Federal guidance. Early education staff was the exception, included in the majority of State priority lists and frequently in the same position as advised by Federal guidance. The majority of States assigned the 65-74 year age group to a higher position than recommended in Federal guidance. Those with underlying medical conditions were similarly highly prioritized, although there was more variability across States. Several socially vulnerable groups not prescriptively included in Federal guidance were often highly prioritized by States, including those living or working in congregate settings and individuals with disabilities.

\subsection{Explaining Disparities between Federal and State}

Several large outbreaks and many associated deaths have been observed in U.S. care homes [12], emphasizing the risk of COVID-19 transmission in such settings. It is therefore unsurprising that staff and residents in long-term care facilities were prioritized by both the CDC and individual States. Healthcare workers are at a high-risk of exposure to COVID19 and have prolonged contact with vulnerable individuals. Among 2,135,190 people in the UK and USA using the COVID-19 Symptom Study app between 24 March and 23 April 2020, front-line health-care workers had at least a threefold increased risk of reporting a positive COVID-19 test compared with the general community [13]. Front-line healthcare workers who worked in inpatient settings had a much greater risk of infection compared to healthcare workers in other settings. This may in part help to explain why although all States prioritized healthcare workers in the very first phase, a few vaccinated those working in the community after those in hospital. Given concerns about vaccine acceptance in healthcare workers $[14,15]$, the success of State programs in vaccinating healthcare workers may vary despite their homogenous prioritization.

The elderly and those with co-morbidities are at a high-risk of severe disease and death from COVID-19 [16,17]. Most States, although not all, did prioritize by age to some degree using a range of thresholds. Federal recommendations positioned both the 65-74 year age group and those with underlying medical conditions in the third phase (1C). A majority of State priority lists assigned a higher priority to the former group, and a smaller proportion of States did the same for the latter group. In part, this may have been due to a Department of Health and Human Services (DHHS) announcement in January 2021 that encouraged States to vaccinate those over 65 years and all those with high-risk medical conditions [18]. The magnitude of the risk of severe disease with increasing age is well-established [16] and likely played a part in the high priority assigned to the 65-74 year age group. Those with underlying conditions were positioned higher than Federal guidance in 20 States. An analysis of over 5 million COVID-19 cases across 3141 U.S. counties [19] found that areas in the most vulnerable quintile (as measured by the CDC Social Vulnerability Index) saw higher rates of COVID-19 cases (rate ratio 2.11, 95\% CI 1.97 to 2.26) and deaths (rate ratio $2.42,95 \%$ CI 2.22 to 2.64 ) compared to the least vulnerable areas. The prevalence of major chronic conditions was $24-41 \%$ higher in the most vulnerable counties. Prioritizing those with medical conditions may have been an attractive option for States looking to minimize health inequalities, as well as being useful in younger populations where not all high-risk individuals would be identified on the basis of age alone.

Federal guidance states preserving the functioning of society as a goal of the U.S. COVID-19 vaccination program, alongside decreasing death and severe disease as well as reducing the burden of COVID-19 on people already facing disparities [10]. There was a clear distinction made across States between prioritizing early education staff and other essential worker groups. This is likely due to the high risk of COVID-19 outbreaks in schools, their prolonged closure, and the associated detriment to child learning and development [20]. States consistently excluded other essential workers from their priority plans. One reason may be due to the size of this group, estimated at around 87 million individuals [21]. There may also have been overlap with groups previously vaccinated, with the majority of essential workers in the U.S. having at least one underlying highrisk medical condition [11]. Where included, many States assigned a lower priority for 
frontline essential workers than advised by Federal guidance. In part this could be due to the relatively low predicted rates of vaccine uptake in the younger working population, relative to other groups [22] as well as State perceptions about the importance of some vaccination program objectives compared to others.

The COVID-19 case rate has been over four times higher in U.S. prisons compared to the general population [23]. The impact of COVID-19 in prisons has varied across States. Ohio had a prison mortality rate that was around 11 times that of the adjusted State mortality rate, whereas six other States reported COVID-19 death rates below adjusted State mortality rates [23]. This may in part explain why those living in congregate settings were included at a relatively high position in some State's vaccine rollout plans but not at all in others. Congregate settings also include assisted living facilities, mental health and substance misuse treatment centers, homeless shelters, and others. Individuals in such settings are at a higher risk of disease acquisition [24] and in many cases severe disease. Vaccinating these socially vulnerable groups during a pandemic can help programs meet principles of equity as well as utility [25], likely making them a priority for many despite a lack of prescriptive Federal guidance. While States included some socially vulnerable groups in priority lists, even in the absence of clear Federal guidance, others were excluded. Despite the high burden of pre-existing disease, poverty, systemic and structural discrimination, lack of access to health services and preventative measures, indigenous populations have been relatively ignored in the U.S. pandemic response to date [26]. It appears that this continues to be the case, with only Montana, New Jersey, Oregon and Utah explicitly prioritizing indigenous or tribal populations for COVID19 vaccination.

\subsection{Technology, Cost and Supply}

The Federal prioritization helps deliver the CDCs objectives for the COVID-19 vaccination program, including reducing transmission and minimizing the risk of morbidity and mortality, minimizing the disruption to society and the economy, and ensuring equity in vaccine allocation and distribution. However, these objectives and the resulting prioritization groups may not necessarily reflect the external constraints imposed by the vaccine technology, its supply and the cost of vaccination programs. Subsequent State guidance may reflect these.

Both the Pfizer and Moderna vaccines use mRNA, which needs to be stored at very low temperatures, therefore the logistics for vaccinating with these candidate vaccines are different from the Oxford-AstraZeneca and Johnson \& Johnson vaccines, which are easier to deploy and handle. The Pfizer and Moderna vaccines were the first approved vaccines in the U.S. Once this logistic consideration is combined with the need to vaccinate as many people as possible as quickly as possible, then priority groups that can be quickly located (those in care homes, health facilities) may be seen as a more effective and cost-effective target. Arguably those at greatest risk, the socially vulnerable groups, may be harder to identify and target, and uptake may be lower.

It is unclear whether States took the cost of vaccinating into account when operationalizing the Federal priority list to create their own priorities. As part of Operation Warp Speed funding has be made available to States, but this appears to be phased [27]. Likewise, the supply constraints of the vaccine may have factored into the States prioritization plans.

\subsection{Strengths and Limitations}

Unlike previous analyzes of U.S. COVID-19 vaccine priority lists [8], this rapid review systematically aggregated States across the country by population group. This allowed us to create a directional measure of disparity between Federal guidance and State practice, for each population group, providing us with a better understanding of how Federal guidance is working differently for some groups compared to others, and the potential implications on equity. 
A key limitation in our analysis was the inability to measure the time taken to progress through different vaccine allocation phases, and how this might vary across States. Given variable vaccine supplies, group sizes, and ways of labelling priority phases, priority groups may not have been directly comparable. For instance, three States (Connecticut, Florida and Mississippi) prioritized several groups in parallel as part of one single phase. Some other States split their rollout into several, smaller phases. To minimize the impact of this on our analysis, we did not use subgroups within phases where reported (e.g., phase 1A.1, 1A.2, 1A.3). As both Federal and State plans prioritized distinct groups, we were able to assess the overall translation of guidance into practice, despite inconsistent methods of prioritization across States. Secondly, it was not possible to assess variation in vaccine prioritization at the County level due to a lack of routinely available published documentation. Finally, the extraction and analysis of data across States was limited by the information available in the public domain, with some priority lists being more extensive than others.

\subsection{Implications for Future Research}

Disparities between Federal guidance and State practice were inconsistent across population groups. Some States have seen a quicker vaccine rollout compared to others [6] This makes it imperative that the long-term impact on all-cause mortality and morbidity is studied within different population groups. Slower progressing State programs omitting socially vulnerable groups from priority lists (as per Federal guidance) may be considered less equitable, through their failure to protect those who most suffer the socioeconomic impacts of infection or non-immunity, for longer. Given the concentration of ill-health prior to the pandemic in low-income, deprived and socially disadvantaged groups, this may be worse for health inequalities but has often been justified on the grounds of speed and simplicity [18]. Understanding the relationship between equity and efficiency in the context of COVID-19 vaccination programs is a key research question that can inform future rollouts, including in countries yet to receive vaccines.

The CDC was largely sidelined during the first phase of the pandemic [28]. Even with sufficient power and credibility, public health guidance issued at the national level may not translate to the local level. Implementation can be limited by a lack of specificity and complexity, particularly when guidance comes into conflict with local evidence. In a UK study of 31 local government employees including public health directors, participants supported an approach of starting with local need and examples of effective practice, to reverse engineer national guidelines [29]. In the case of COVID-19 vaccines, prioritization recommendations may be improved through qualitative research with State decisionmakers and citizens, for instance in the form of Citizen Councils [30], to ascertain the range of local values, needs and constraints that should be reflected in Federal guidance.

\section{Conclusions}

The prioritization of groups for COVID-19 vaccination has been highly variable across the U.S, despite clear Federal guidance. For healthcare workers and those in long-term care facilities, there is little variation. Other than early education staff, many essential workers were altogether excluded from several State priority plans. Where included, they were often assigned a lower priority position compared to Federal guidance. On the other hand, first responders, those aged 65-74 years and those with underlying conditions were frequently assigned to a higher priority position. Socially vulnerable groups such as those living in congregate settings and the disabled were highly prioritized in State plans, despite not forming a distinct priority group in Federal guidance. Few States included indigenous or low-income populations in their lists, suggesting that there is a great deal of variability in social value judgements and perceived needs for vaccines, which are currently not reflected in Federal guidance. It may also be that the Federal guidance does not reflect the constraints that States are working within, such that the difference in priorities could be due to idealism at the Federal level versus realism at the State level. Future policy must aim to ensure that guidance issued at the Federal level is relevant and sensitive to local 
needs, acknowledges potential funding and distribution limitations at the local level, and can be implemented in a way that minimizes any unwarranted heterogeneity in vaccine access across populations.

Author Contributions: All authors (V.J., L.S., P.L.) contributed to the conceptualization, design, and methodology of the study. V.J. and L.S. extracted all data. All authors were involved in subsequent analysis and interpretation of the data, writing the initial draft of the manuscript as well as reviewing, editing and approving the final version for publication. All authors have read and agreed to the published version of the manuscript.

Funding: No funding was required or obtained for this study.

Institutional Review Board Statement: Not applicable.

Informed Consent Statement: Not applicable.

Data Availability Statement: The dataset is available upon request from interested parties after the manuscript has been peer-reviewed and published.

Conflicts of Interest: The authors declare no conflict of interest.

\section{References}

1. Whitehead, M. The concepts and principles of equity and health. Health Promot Int. 1991, 6, 217-228. [CrossRef]

2. Gordon, S.H.; Huberfeld, N.; Jones, D.K. What Federalism Means for the US Coronavirus Disease 2019 Response. JAMA Health Forum Am. Med. Assoc. 2020, 1, e200510. [CrossRef]

3. Gostin, L.O.; Wiley, L.F. Governmental public health powers during the COVID-19 pandemic: Stay-at-home orders, business closures, and travel restrictions. JAMA 2020, 323, 2137-2138. [CrossRef] [PubMed]

4. Centers for Disease Control and Prevention (CDC). Mask Requirement. 2021. Available online: https://www.cdc.gov/ coronavirus/2019-ncov/travelers/face-masks-public-transportation.html (accessed on 24 February 2021).

5. Iacobucci, G. Covid-19: Increased risk among ethnic minorities is largely due to poverty and social disparities, review finds. BMJ Br. Med. J. 2020, 371. [CrossRef] [PubMed]

6. The New York Times. See How the Vaccine Rollout Is Going in Your State. 2021. Available online: https:/ / www.nytimes.com/ interactive/2020/us/covid-19-vaccine-doses.html (accessed on 24 February 2021).

7. Centers for Disease Control and Prevention (CDC). COVID Data Tracker. 2021. Available online: https://covid.cdc.gov/coviddata-tracker/\#datatracker-home (accessed on 20 February 2021).

8. Kaiser Family Foundation. The COVID-19 "Vaccination Line": An Update on State Prioritization Plans. 2021. Available online: https:/ / www.kff.org/coronavirus-covid-19/issue-brief/the-covid-19-vaccination-line-an-update-on-state-prioritizationplans/ (accessed on 28 February 2021).

9. Centers for Disease Control and Prevention (CDC). The Importance of COVID-19 Vaccination for Healthcare Personnel. 2020. Available online: https: / /www.cdc.gov/coronavirus/2019-ncov/vaccines/recommendations/hcp.html (accessed on 25 February 2021).

10. Centers for Disease Control and Prevention (CDC). CDC's COVID-19 Vaccine Rollout Recommendations. 2021. Available online: https:/ / www.cdc.gov/ coronavirus/2019-ncov/vaccines/recommendations.html (accessed on 3 February 2021).

11. Centers for Disease Control and Prevention (CDC). The Advisory Committee on Immunization Practices' Updated Interim Recommendation for Allocation of COVID-19 Vaccine-United States, December 2020. 2021. Available online: https:/ /www.cdc. gov/mmwr/volumes/69/wr/mm695152e2.htm?s_cid=mm695152e2_w (accessed on 26 February 2021).

12. Thompson, D.C.; Barbu, M.G.; Beiu, C.; Popa, L.G.; Mihai, M.M.; Berteanu, M.; Popescu, M.N. The impact of COVID-19 pandemic on long-term care facilities worldwide: An overview on international issues. BioMed Res. Int. 2020, 8870249. [CrossRef] [PubMed]

13. Nguyen, L.H.; Drew, D.A.; Graham, M.S.; Joshi, A.D.; Guo, C.G.; Ma, W.; Mehta, R.S.; Warner, E.T.; Sikavi, D.R.; Lo, C.H.; et al. Risk of COVID-19 among front-line health-care workers and the general community: A prospective cohort study. Lancet Public Health 2020, 5, e475-e483. [CrossRef]

14. Shekhar, R.; Sheikh, A.B.; Upadhyay, S.; Singh, M.; Kottewar, S.; Mir, H.; Barrett, E.; Pal, S. COVID-19 vaccine acceptance among health care workers in the United States. Vaccines 2021, 9, 119. [CrossRef] [PubMed]

15. Szmyd, B.; Karuga, F.F.; Bartoszek, A.; Staniecka, K.; Siwecka, N.; Bartoszek, A.; Błaszczyk, M.; Radek, M. Attitude and Behaviors towards SARS-CoV-2 Vaccination among Healthcare Workers: A Cross-Sectional Study from Poland. Vaccines 2021, 9, 218. [CrossRef]

16. Centers for Disease Control and Prevention (CDC). People Who Are at Higher Risk for Severe Illness. 2020. Available online: https:/ / www.cdc.gov/coronavirus/2019-ncov/need-extra-precautions/people-at-higher-risk.html (accessed on 20 April 2020).

17. Williamson, E.J.; Walker, A.J.; Bhaskaran, K.; Bacon, S.; Bates, C.; Morton, C.E.; Curtis, H.J.; Mehrkar, A.; Evans, D.; Inglesby, P.; et al. Factors associated with COVID-19-related death using OpenSAFELY. Nature 2020, 584, 430-436. [CrossRef] [PubMed] 
18. Kaiser Family Foundation. The COVID-19 Vaccine Priority Line Continues to Change as States Make Further Updates. 2021. Available online: https://www.kff.org/policy-watch/the-covid-19-vaccine-priority-line-continues-to-change-as-states-makefurther-updates/ (accessed on 3 January 2021).

19. Islam, N.; Lacey, B.; Shabnam, S.; Erzurumluoglu, A.M.; Dambha-Miller, H.; Chowell, G.; Kawachi, I.; Marmot, M. Social inequality and the syndemic of chronic disease and COVID-19: County-level analysis in the USA. J. Epidemiol. Community Health 2021. [CrossRef] [PubMed]

20. Dorn, E.; Hancock, B.; Sarakatsannis, J.; Viruleg, E. COVID-19 and Student Learning in the United States: The Hurt Could Last a Lifetime; McKinsey \& Company: Brussels, Belgium, 2020; pp. 1-9.

21. Centers for Disease Control and Prevention (CDC). Phased Allocation of COVID-19 Vaccines. 2020. Available online: https: / / www.cdc.gov/vaccines/acip/meetings/downloads/slides-2020-11/COVID-04-Dooling.pdf (accessed on 3 January 2021).

22. Centers for Disease Control and Prevention (CDC). COVID-19 Vaccination Intent, Perceptions, and Reasons for Not Vaccinating among Groups Prioritized for Early Vaccination-United States, September and December 2020. 2021. Available online: https:/ / www.cdc.gov/mmwr/volumes/70/wr/mm7006e3.htm (accessed on 3 February 2021).

23. National Commission on COVID-19 and Criminal Justice. Impact Report: COVID-19 and Prisons. 2020. Available online: https:/ / covid19.counciloncj.org/2020/09/02/covid-19-and-prisons / (accessed on 3 February 2021).

24. Mishra, S.; Kwong, J.C.; Chan, A.K.; Baral, S.D. Understanding heterogeneity to inform the public health response to COVID-19 in Canada. CMAJ 2020, 192, E684-E685. [CrossRef] [PubMed]

25. Buccieri, K.; Gaetz, S. Ethical vaccine distribution planning for pandemic influenza: Prioritizing homeless and hard-to-reach populations. Public Health Ethics 2013, 6, 185-196. [CrossRef]

26. Curtice, K.; Choo, E. Indigenous populations: Left behind in the COVID-19 response. Lancet 2020, 395, 1753. [CrossRef]

27. US Department of Defense. Coronavirus: Operation Warp Speed. 2021. Available online: https://www.defense.gov/Explore/ Spotlight/Coronavirus/Operation-Warp-Speed/ (accessed on 11 March 2021).

28. The Wall Street Journal. More Than 1000 Current and Former CDC Officers Criticize U.S. Covid-19 Response. 2020. Available online: https: / / www.wsj.com/articles/more-than-1-000-current-and-former-cdc-officers-condemn-u-s-covid-19-response-11 602884265 (accessed on 22 February 2021).

29. Atkins, L.; Kelly, M.P.; Littleford, C.; Leng, G.; Michie, S. Reversing the pipeline? Implementing public health evidence-based guidance in english local government. Implement. Sci. 2017, 12, 1-13. [CrossRef] [PubMed]

30. Shah, K.K.; Cookson, R.; Culyer, A.J.; Littlejohns, P. NICE's Social Value Judgements about Equity in Health Care and Health Care. Health Econ. Pol'y L 2013, 8, 145. [CrossRef] [PubMed] 